\begin{tabular}{|c|l|}
\hline Title & Natural oxides on air-exposed and chemically treated InGaP surfaces grown by metal organic vapor phase epitaxy \\
\hline Author(s) & Hashizume, Tamotsu; Saitoh, Toshiya \\
\hline Citation & $\begin{array}{l}\text { A pplied Physics Letters, 78(16), 2318-2320 } \\
\text { https://doi.org/10.1063/1366648 }\end{array}$ \\
\hline Issue Date & 2001-0416 \\
\hline Doc URL & http://hdl.handle.net/2115/5544 \\
\hline Rights & Copyright $\odot 2001$ A merican Institute of Physics \\
\hline Type & article \\
\hline File Information & APL 78-16.pdf \\
\hline
\end{tabular}

Instructions for use 


\title{
Natural oxides on air-exposed and chemically treated InGaP surfaces grown by metalorganic vapor phase epitaxy
}

\author{
Tamotsu Hashizume ${ }^{\text {a) }}$ \\ Research Center for Interface Quantum Electronics (RCIQE), Hokkaido University, Sapporo, \\ 060-8628, Japan \\ Toshiya Saitoh \\ Hitachi Cable Ltd., Hitachi, 319-14, Japan
}

(Received 11 December 2000; accepted for publication 20 February 2001)

\begin{abstract}
Chemical properties of natural oxides on air-exposed and chemically treated $\operatorname{In}_{0.49} \mathrm{Ga}_{0.51} \mathrm{P}$ surfaces grown by metalorganic vapor phase epitaxy were systematically investigated by $\mathrm{X}$-ray photoelectron spectroscopy. An air-exposed sample exhibited a highly In-rich surface which included a large amount of natural oxides. From the valence-band spectra and energy separations between core levels, it was found that the $\mathrm{InPO}_{4}$-like chemical phase was dominant in natural oxides of air-exposed InGaP surfaces. Chemical surface treatments in $\mathrm{HCl}$ and $\mathrm{HF}$ solutions were effective in reducing natural oxide and in recovering the surface stoichiometry. (C) 2001 American Institute of Physics. [DOI: 10.1063/1.1366648]
\end{abstract}

InGaP and lattice-matched InGaP/GaAs heterostructures are now well established as materials for the production of high-power/high-frequency devices such as heterojunction bipolar transistors and high-electron mobility transistors. These are key devices for the next-generation wireless communication systems, e.g., International Mobile Telecommunications-2000 (IMT-2000). Reproducibility of the device fabrication process and reliability of the device operation are indispensable for realization of highperformance wireless systems. In this regard, surface and interface issues are very important. However, the variety of surface atomic arrangement of InGaP due to the well-known sublattice ordering effects ${ }^{1-3}$ and an As/P intermixing at the phosphide/arsenide interface ${ }^{4,5}$ make the control of surfaces and heterointerfaces rather complicated and difficult. In actual device fabrication process, in addition, unexpected interfacial chemical reactions can take place during the formation process of metal-semiconductor and insulator-semiconductor interfaces, reducing the reproducibility of the device processing. However, surface chemistry of InGaP has not been explored in detail.

In this letter, surface chemical properties of air-exposed and chemically treated $\mathrm{In}_{0.49} \mathrm{Ga}_{0.51} \mathrm{P}$ grown by metalorganic vapor phase epitaxy (MOVPE) were systematically investigated by x-ray photoelectron spectroscopy (XPS).

Si-doped $\operatorname{In}_{0.49} \mathrm{Ga}_{0.51} \mathrm{P}$ epitaxial layers were grown on $n^{+} \mathrm{GaAs}(001)$ substrates at $580{ }^{\circ} \mathrm{C}$ by MOVPE with trymethylindium, triethylgallium, and phosphine. The layer thickness of InGaP was approximately $0.6 \mu \mathrm{m}$, and the carrier concentration of the grown layer was determined to be 6 $\times 10^{16} \mathrm{~cm}^{-3}$ by a capacitance-voltage method. The band edge photoluminescence at RT was found at $1.85 \mathrm{eV}$, corresponding to an ordering parameter, $\eta$, of $0.35-0.40 .^{6}$ Preliminary deep level transient spectroscopy study showed that no pronounced electron trap with the density higher than 1 $\times 10^{14} \mathrm{~cm}^{-3}$ was found in the InGaP layer.

Properties of natural oxide on as-grown and air-exposed InGaP surfaces were investigated at first. Then we examined effects of the wet chemical treatments using the three kinds of solutions: (i) a $\mathrm{NH}_{4} \mathrm{OH}$ solution at $50{ }^{\circ} \mathrm{C}$ for $10 \mathrm{~min}$, (ii) a $\mathrm{HCl}: \mathrm{H}_{2} \mathrm{O}=1: 1$ solution at $\mathrm{RT}$ for $2 \mathrm{~min}$, and (iii) $\mathrm{HF}: \mathrm{C}_{2} \mathrm{H}_{5} \mathrm{OH}=1: 5$ solution at $\mathrm{RT}$ for $2 \mathrm{~min}$. The surface chemical properties of InGaP layers were characterized by the XPS method. It took about 30 min to transfer the samples to the XPS chamber after the wet chemical treatments. The XPS measurement system (Perkin Elmer PHI 1600C) consists of a spherical capacitor analyzer and a monochromated Al $K \alpha$ x-ray source $(h \nu=1486.6 \mathrm{eV})$.

Figure 1 shows XPS survey spectra obtained from an air-exposed InGaP surface. As compared to the spectrum with the electron escape angle of $45^{\circ}$, high intensity of the $\mathrm{O} 1 s$ peak was observed in the surface-sensitive spectrum (electron escape angle of $15^{\circ}$ ). In addition, highly depletion of the Ga $2 p$ intensity was observed. These results clearly indicated that an In-rich natural oxide existed on the topmost surface of air-exposed InGaP.

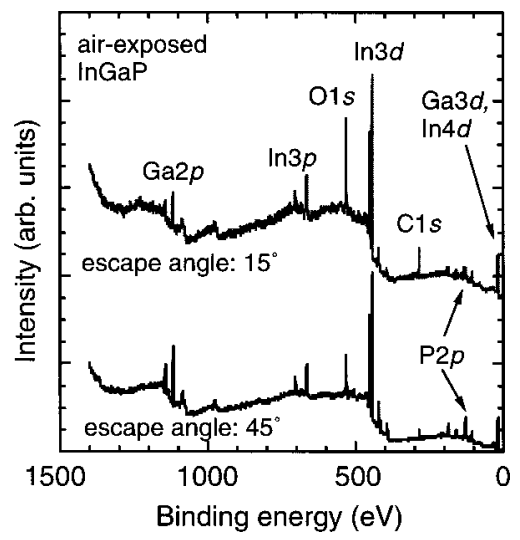

FIG. 1. XPS survey spectra of an air-exposed InGaP surface.

${ }^{a)}$ Electronic mail: hashi@rciqe.hokudai.ac.jp 


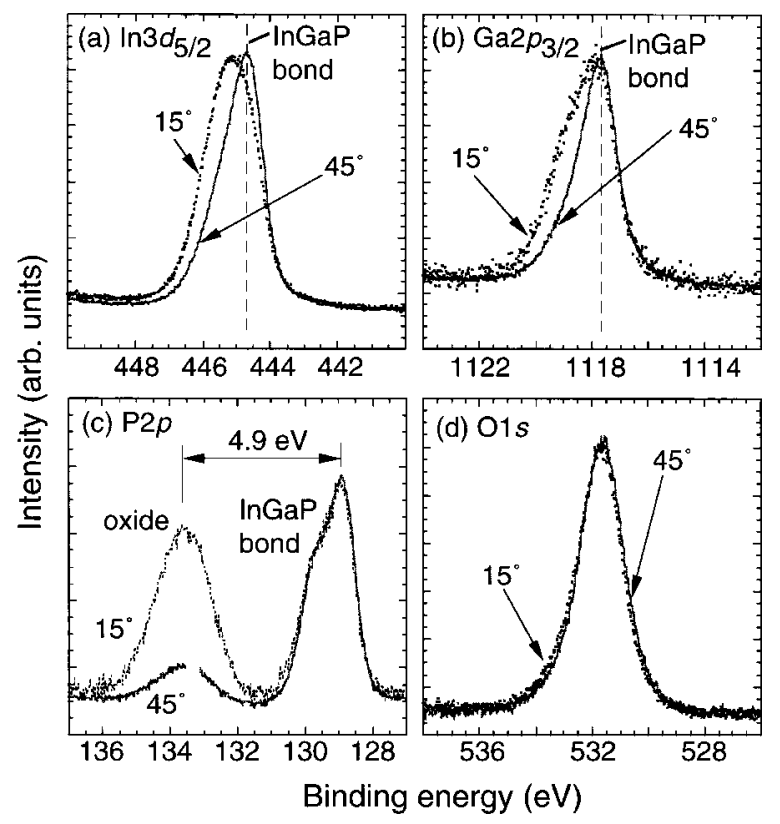

FIG. 2. XPS core-level spectra of an air-exposed InGaP surface. The peak heights were adjusted at each spectra for comparison.

Narrow scans of the In $3 d_{5 / 2}$, Ga $2 p_{3 / 2}, \mathrm{P} 2 p$, and $\mathrm{O} 1 \mathrm{~s}$ spectra taken with electron escape angles of $15^{\circ}$ and $45^{\circ}$ are shown in Fig. 2. For comparison, the peak heights were adjusted at each spectra. The In $3 d$ signal at an electron escape angle of $15^{\circ}$ exhibited broad spectra with the peak shift to higher binding energies in comparison with that taken at $45^{\circ}$, indicating that the surface spectrum included a large amount of an oxide component. An asymmetric feature appeared in the $\mathrm{Ga} 2 p$ core-level spectrum at $15^{\circ}$, as shown in Fig. 2(b). A shoulder at higher binding energies is attributed to the Ga oxide. However, the intensity of Ga $2 p$ peak was about $20 \%$ of the In $3 d$ peak, in spite of the fact that the XPS sensitivity factors are almost the same for these two core levels. In the P $2 p$ spectrum [Fig. 2(c)], an additional peak with the chemical shift of $4.9 \mathrm{eV}$ against the pure In$\mathrm{GaP}$ bond was clearly seen. High intensity of the $\mathrm{O} 1 s$ peak was detected at $531.7 \mathrm{eV}$ for the air-exposed surface. These

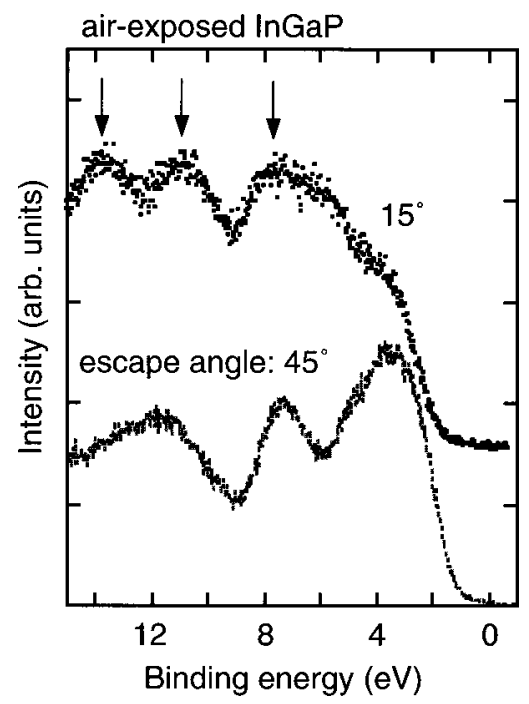

FIG. 3. Valence-band spectra of an air-exposed InGaP surface.

Downloaded 24 Feb 2006 to 133.87.26.100. Redistribution subject to AlP license or copyright, see http://apl.aip.org/apl/copyright.jsp

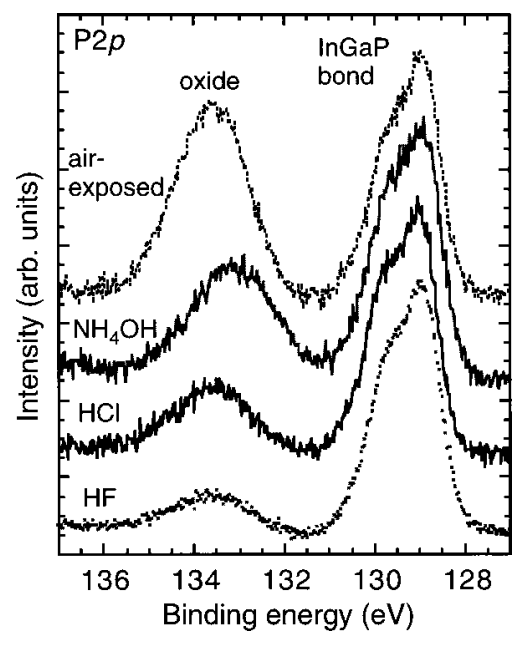

FIG. 4. P $2 p$ spectra with electron escape angle of $15^{\circ}$ before and after chemical surface treatments. The peak heights of the InGaP bonds were adjusted for comparison.

results indicated that the air-exposed InGaP surface was covered by a natural oxide layer with highly In-rich phase.

In order to obtain a better insight into the chemical phase, we measured the valence-band spectra and energy separations between the $\mathrm{O} 1 s$ peak and the oxide peaks in each core level. Figure 3 shows the measured valence-band spectra of the air-exposed InGaP surface. The spectrum with the escape angle of $45^{\circ}$ mainly originating from the bulk electronic band structure was similar to those of the basebinary materials, InP and GaP. On the other hand, the spectrum with the escape angle of $15^{\circ}$ was very different from the bulk one, reflecting an electronic structure of the surface natural oxide. In comparison with the previous report, ${ }^{7}$ the spectrum is rather similar to that of $\mathrm{InPO}_{4}$, one of the native oxides of InP. This is also confirmed by the values of the $\mathrm{O} 1 s$ peak energy, energy separations between main core levels in oxide phases, and the chemical shifts in $\mathrm{P} 2 p$ levels, as summarized in Table I. The values for $\mathrm{In}_{2} \mathrm{O}_{3}, \mathrm{Ga}_{2} \mathrm{O}_{3}$, $\mathrm{P}_{2} \mathrm{O}_{5}$, and $\mathrm{InPO}_{4}$ were taken from Refs. 7 and 8. The position of the $\mathrm{O} 1 s$ peak as well as the $\mathrm{O} 1 s-\mathrm{In} 3 d$ and $\mathrm{O} 1 s-\mathrm{P} 2 p$ energy separations are very close to those of $\mathrm{InPO}_{4}$. In the P $2 p$ level, in addition, the chemical shift of the oxide phase from the InGaP bond peak was found to be $4.9 \mathrm{eV}$, almost corresponding to the value in $\mathrm{InPO}_{4}$. All these results indicated that the $\mathrm{InPO}_{4}$-like oxide was dominant on air-exposed InGaP surfaces. In fact, the atomic composition of $\operatorname{InP}_{0.8} \mathrm{O}_{3.7}$ was estimated for the oxide phase from the XPS integrated intensities of the $\mathrm{O} 1 s$, In $3 d_{5 / 2}$, and $\mathrm{P} 2 p$ levels.

TABLE I. The O $1 s$ peak energies, energy separations, and chemical shifts of oxide phases in $\mathrm{P} 2 p$ spectra in the unit of electron volts.

\begin{tabular}{cccccc}
\hline \hline Oxides & $\mathrm{O} 1 s$ & $\mathrm{O} 1 s-\mathrm{In} 3 d$ & $\mathrm{O} 1 s-\mathrm{P} 2 p$ & $\mathrm{O} 1 s-\mathrm{Ga} 3 d$ & $\begin{array}{c}\text { Chemical shift } \\
\text { in } \mathrm{P} 2 p\end{array}$ \\
\hline $\mathrm{In}_{2} \mathrm{O}_{3}{ }^{\mathrm{a}}$ & 530.2 & 85.5 & & & \\
$\mathrm{P}_{2} \mathrm{O}_{5}{ }^{\mathrm{a}}$ & 534.1 & & 398.5 & & 6.8 \\
$\mathrm{Ga}_{2} \mathrm{O}_{3}{ }^{\mathrm{b}}$ & 531.1 & & & 510.7 & \\
$\mathrm{InPO}_{4}{ }^{\mathrm{a}}$ & 531.8 & 86.1 & 397.7 & & 5.3 \\
$\begin{array}{c}\mathrm{InGaP} \\
\text { oxide }\end{array}$ & 531.7 & 86.3 & 397.9 & 511.3 & 4.9 \\
\hline \hline
\end{tabular}

${ }^{a}$ See Ref. 7. 


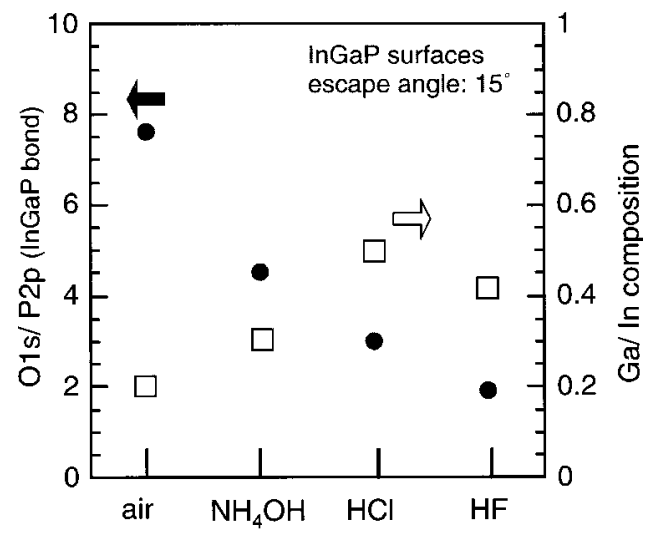

FIG. 5. Changes in the normalized O $1 s$ peak intensities by the InGaP-bond intensities in the P $2 p$ spectra and the $\mathrm{Ga} / \mathrm{In}$ atomic composition ratios before and after chemical surface treatments.

The reason why the $\mathrm{InPO}_{4}$ component is dominant in the natural oxide of an as-grown and air-exposed $\mathrm{InGaP}$ surface is not clear yet. Concerning the structural properties of Pand In-related oxides, phosphorous has a tetrahedral oxygen coordination, whereas indium is surrounded by six oxygen atoms at the corner of an octahedron. ${ }^{9,10} \mathrm{InPO}_{4}$ consists of columns of edge-sharing $\mathrm{InO}_{6}$ octahedra connected by $\mathrm{PO}_{4}$ tetrahedra. ${ }^{10}$ In the valence-band spectra shown in Fig. 3, three peaks at around 8, 11, and $14 \mathrm{eV}$ appeared. The tightbinding calculation of electronic structures of InP oxides ${ }^{9}$ has shown that these peaks arise from the $\mathrm{O} 2 p$ atomic orbital energies, the $\mathrm{O} 2 p-\mathrm{P} 3 p$ orbital interaction and the O $2 p-\mathrm{P} 3 s$ orbital interaction, respectively.

Figure 4 shows the P $2 p$ spectra of InGaP surfaces before and after chemical treatments. Again, the peak heights of the $\mathrm{InGaP}$ bond were adjusted for comparison. As seen, all the treatments effectively decreased the intensity of the oxide phase in the $\mathrm{P} 2 p$ level. For the In $3 d$ and Ga $2 p$ spectra (not shown here), symmetric features with the narrowing of linewidths and noticeable peak shifts towards lower binding energies were observed after these treatments. The effects of the chemical treatments on the control of the InGaP surface were summarized in Fig. 5, in terms of the normalized $\mathrm{O} 1 \mathrm{~s}$ peak intensity by the InGaP-bond intensity in the $\mathrm{P} 2 p$ spectra and the $\mathrm{Ga} / \mathrm{In}$ atomic composition ratio. $\mathrm{A} \mathrm{HCl}$ solution is known to act as an etchant for InP and InGaP, thereby reducing natural oxide of InGaP. Further reduction of the ox- ide intensity was realized by the HF treatment which is known to be effective in removing the InP natural oxide mainly consisting of $\mathrm{InPO}_{4}{ }^{11}$ This strongly supported the present finding that the natural oxide on air-exposed $\mathrm{InGaP}$ surfaces dominantly possessed the $\mathrm{InPO}_{4}$-like chemical phase. With the reduction of the O $1 s$ intensity, the $\mathrm{Ga} / \mathrm{In}$ composition was recovered to the value of 0.4-0.5. Separate electrical measurements showed that the present chemical treatments, namely the $\mathrm{HCl}$ and $\mathrm{HF}$ treatments, improved Schottky contact properties. After the treatments, the ideality factor, $n$, lowered from 1.21 to 1.04 and the reverse leakage current was reduced by a factor of 20 .

In summary, surface chemistry of air-exposed and chemically treated $\operatorname{In}_{0.49} \mathrm{Ga}_{0.51} \mathrm{P}$ grown by MOVPE was systematically investigated by XPS. An air-exposed sample showed highly nonstoichiometric (In-rich) surface which included a large amount of natural oxides. Analyses on the valence-band spectra and core-level energy separations indicated that the $\mathrm{InPO}_{4}$-like component was dominant on airexposed InGaP surfaces. Chemical surface treatments, namely in $\mathrm{HCl}$ and $\mathrm{HF}$ solutions, were found to be effective in reducing natural oxide, leading to the recovery of surface stoichiometry.

This work was partly supported by a grant-in-aid for Scientific Research (B) (No. 11555081) and (C) (No. 11650309) from the Ministry of Science, Education, Sports, and Culture, Japan.

${ }^{1}$ A. Gomyo, T. Suzuki, and S. Iijima, Phys. Rev. Lett. 60, 2645 (1988).

${ }^{2}$ K. A. Mäder and A. Zunger, Phys. Rev. B 51, 10462 (1995).

${ }^{3}$ S. Froyen, A. Zunger, and A. Mascarenhas, Appl. Phys. Lett. 68, 2852 (1996).

${ }^{4}$ O. Schuler, O. Dehaese, X. Wallert, and F. Mollot, J. Appl. Phys. 84, 765 (1998).

${ }^{5}$ C. Cai and M. I. Nathan, J. Vac. Sci. Technol. B 18, 2096 (2000).

${ }^{6}$ P. Ernst, C. Geng, F. Scholz, H. Schweizer, Y. Zhang, and A. Mascarenhas, Appl. Phys. Lett. 67, 2347 (1995).

${ }^{7}$ G. Hollinger, E. Bergignat, J. Joseph, and Y. Robach, J. Vac. Sci. Technol. A 3, 2082 (1985).

${ }^{8}$ G. Hollinger, R. Skheyta-Kabbani, and M. Gendry, Phys. Rev. B 49, 11159 (1994)

${ }^{9}$ S. J. Sferco, G. Allan, I. Lefebvre, M. Lannoo, E. Bergignat, and G. Hollinger, Phys. Rev. B 42, 11232 (1990).

${ }^{10}$ Y. Robach, M. P. Besland, J. Joseph, G. Hollinger, P. Viktorovitch, P. Ferret, M. Pitaval, A. Falcou, and G. Post, J. Appl. Phys. 71, 2981 (1992).

${ }^{11}$ A. Guivarc'h, H. L'Haridon, G. Pelous, G. Hollinger, and P. Pertosa, J. Appl. Phys. 55, 1139 (1984). 